\title{
Virulência, Atividade Enzimática e Padrões de Isoesterases de Isolados de Pyrenophora chaetomioides, Agente Etiológico da Mancha de Grãos e Folhas de Aveia*
}

\author{
Carla A. C. Bocchese ${ }^{* * 1}$, José A. Martinelli' ${ }^{1}$ Aida T. S. Matsumura ${ }^{1}$; \\ Luíz C. Federizzi**2 \& Ariano M. Prestes**3 \\ ${ }^{1}$ Departamento de Fitossanidade; ${ }^{2}$ Departamento de Plantas de Lavoura, Faculdade de Agronomia, \\ UFRGS, Cx. Postal 776, 90012-970, Porto Alegre, RS; ${ }^{3}$ Embrapa Trigo, BR 285, Km 174, Passo Fundo, RS
}

(Aceito para publicação em 31/10/2002)

Autor para correspondência: José Antônio Martinelli

BOCCHESE, C.A.C., MARTINELLI, J.A., MATSUMURA, A.T.S., FEDERIZZI, L.C. \& PRESTES, A.M. Virulência, atividade enzimática e padrões de isoesterases de isolados de Pyrenophora chaetomioides, agente etiológico da mancha de grãos e folhas de aveia. Fitopatologia Brasileira 28:011-016. 2003.

\section{RESUMO}

A complexidade da população de Pyrenophora chaetomioides, principal agente causal da mancha da folha e do grão de aveia (Avena sativa) no Sul do Brasil, é pouco conhecida. Deste modo, estudos envolvendo a variabilidade da população do patógeno embasarão o desenvolvimento de variedades resistentes. Para a realização deste trabalho, foram selecionados oito isolados de $P$. chaetomioides a partir de sementes de aveia dos três estados do sul do Brasil. Para testar a virulência, os isolados foram inoculados em seis variedades de aveia, avaliando-se a severidade e o tipo de lesão. Todas as variedades de aveia testadas foram suscetíveis aos isolados, embora variações na intensidade de doença tenham sido observadas. Os isolados foram avaliados quanto às suas características amilolíticas, proteolíticas e lipolíticas, utilizando-se meios sólidos para análise destes complexos enzimáticos. $\mathrm{O}$ estudo da caracterização enzimática dos isolados revelou a associação de uma alta atividade enzimática com os isolados mais virulentos. Já a análise dos padrões isoenzimáticos de $\alpha$ e $\beta$ esterases mostrou alta variabilidade entre os isolados com sete perfis distintos identificados mas sem relação com a virulência em plântulas de aveia.

Palavras-chave adicionais: Avena sativa, helmintosporiose, isoenzimas, enzimas.

\section{ABSTRACT}

Virulence, enzymatic activity and isoesterase patterns of isolates of Pyrenophora chaetomioides, causal agent of the oat leaf and kernel spot

The complexity of the population of Pyrenophora chaetomioides, the major causal agent of the oat (Avena sativa) leaf and kernel spot, is not well known in south Brazil. Therefore, studies on population diversity are useful to the breeding programs aimed at obtaining genetic resistance. In this work, eight isolates were selected from oat seeds harvested in the three southern Brazilian States. In order to test their virulence, the isolates were inoculated on six oat varieties and evaluated for disease severity and lesion type. All cultivars were susceptible to the isolates tested although variation in disease intensity among them was noticed. In another study, the isolates were evaluated in relation to their amilolytic, proteolytic and lipolytic activities on enzyme-specific media. Results from the inoculations on six oat cultivars showed a correlation between higher enzymatic activity and virulence of the isolates. Also, their $\alpha$ and $\beta$ esterase patterns were compared by polyacrylamide gel electrophoresis. Seven distinct isoenzymatic patterns of $\alpha$ and $\beta$ esterase were observed among the isolates, although they were not correlated with virulence on oat seedlings.

\section{INTRODUÇÃO}

Atualmente, as manchas de folhas e grãos de aveia (Avena sativa L.) causadas pelo fungo Pyrenophora chaetomioides Speg. (sin. P. avenae Ito \& Kurib) (Sivanesan, 1987; Zhang \& Berbee, 2001), vêm se destacando em termos de incidência e severidade no sul do Brasil. Após o estabelecimento do patógeno na folha, um dano adicional é imposto sobre os grãos, na forma de manchas, os quais são rejeitados

\footnotetext{
* Parte da dissertação de Mestrado do primeiro autor. Universidade Federal do Rio Grande do Sul (2000).

** Bolsistas do CNPq
}

pela indústria alimentícia, proporcionando sérios prejuízos ao produtor. As condições para o controle da doença, no entanto, são ainda muito limitadas em função, principalmente, da falta de informações sobre o patógeno.

$\mathrm{Na}$ bibliografia consultada, não foram encontradas publicações sobre análise de variabilidade na virulência ou incorporação de resistência a $P$. chaetomioides no Brasil. Fontes de resistência a essa doença, no entanto, têm sido relatadas e transferidas com sucesso (Sabesta et al., 1996), originando variedades com altos índices de resistência. No Sul do Brasil, trabalhos com este objetivo estão em fase inicial, sendo que alguns resultados sugerem a existência de 
resistência a $P$. chaetomioides em variedades oriundas dos programas de melhoramento locais (Lângaro et al., 2000). Um maior conhecimento da variabilidade fisiológica de $P$. chaetomioides é de fundamental importância para programas de melhoramento da aveia visando à obtenção de variedades resistentes.

A análise de isoenzimas e proteínas tem sido preconizada por diversos pesquisadores (Alfenas et al., 1982, 1984; Alfenas, 1983; Bernier et al., 1983; Jeng \& Rubbes, 1983; Burdon \& Roelfs, 1985) como um método simples e rápido para identificação e caracterização da virulência de fitopatógenos, como Puccinia graminis Pers.: Pers., P. recondita Robege ex Desmaz, Ceratocystis ulmi (Buisman) C. Moreau e Cryphonectria cubensis (Bruner) Hodges, podendo ser empregada como suporte aos resultados de inoculações em hospedeiros diferenciadores. Alfenas (1983) associou a variabilidade em virulência com padrões isoenzimáticos. Um dos sistemas comumente utilizados é o de esterase, já que a mesma está relacionada com a patogenicidade, além de ser polimórfica e de fácil detecção (Kunoh et al., 1988; Deising et al., 1992; Pascholati et al., 1993).

A análise da produção enzimática de fungos em meio sólido proposta por Hankin \& Anagnostakis (1975) também é considerada um método simples e rápido para a identificação de variantes genéticas em uma população, pela presença ou ausência de enzimas específicas, havendo a possibilidade de associação entre a produção de enzimas extracelulares do patógeno e seu grau de virulência com o hospedeiro.

Desta forma, o objetivo deste trabalho foi comparar os padrões isoenzimáticos e a produção de enzimas extracelulares de oito isolados de $P$. chaetomioides com diferentes níveis de virulência.

\section{MATERIAIS E MÉTODOS}

\section{Obtenção dos isolados}

Os oito isolados de $P$. chaetomioides foram obtidos de sementes de aveia UFRGS-14, UFRGS-15, UPF-16 e Aveia Preta procedentes do cultivo nos três estados produtores de aveia do Brasil (RS, SC e PR). Estes isolados, identificados segundo Ellis (1971), foram mantidos em meio de cultura de BDA na forma polispórica, a $4{ }^{\circ} \mathrm{C}$ por 20 dias, sem a utilização de repicagens sucessivas para a manutenção do inóculo.

\section{Virulência dos isolados}

Para testar a virulência dos isolados, utilizaram-se as cinco variedades de aveia branca UPF-17, UPF-16, UFRGS15, UFRGS-18, UFRGS-14 e uma de Aveia Preta, as quais foram previamente selecionadas a campo quanto ao seu comportamento frente à doença. Dez sementes de cada variedade foram semeadas em potes plásticos $(10 \mathrm{~cm}$ de altura $\mathrm{x}$ $10 \mathrm{~cm}$ de diâmetro), com capacidade aproximada para $500 \mathrm{~g}$ de solo. Os potes foram mantidos em casa de vegetação com fotoperíodo de $12 \mathrm{~h}$, e temperatura ajustada para $22^{\circ} \mathrm{C}$. Após a germinação das sementes, fez-se o desbaste para sete plântulas por pote.
Para a produção de inóculo, os isolados foram cultivados em meio V-8 agar a $23{ }^{\circ} \mathrm{C}$ sob luz negra por 17 dias. Logo após, para cada isolado, o inóculo foi preparado através da remoção dos conídios produzidos em 18 placas, com o auxílio de um pincel e água destilada contendo Tween 20. Após as remoções, as suspensões foram agitadas em um liqüidificador por aproximadamente $1 \mathrm{~min}$, seguindo a contagem dos esporos com auxílio de hematocitômetro e do ajuste e padronização das suspensões para $2 \times 10^{4}$ conídios $/ \mathrm{ml}$. Utilizaram-se $140 \mathrm{ml}$ da suspensão de inóculo de cada isolado para ser pulverizado sobre as seis diferentes cultivares. Para cada cultivar, foram inoculadas quatro repetições, definidas como quatro potes, contendo sete plântulas cada um, totalizando 28 plântulas por variedade para cada isolado. Como testemunha, utilizou-se apenas água destilada.

A inoculação foi feita quando as plântulas atingiram o estádio de duas folhas completamente expandidas e, em seguida, foram colocadas numa câmara de nevoeiro, por 72 h, a $20{ }^{\circ} \mathrm{C}$ e umidade relativa superior a $90 \%$. Após este período, as plântulas foram transferidas para casa de vegetação onde permaneceram até a avaliação dos sintomas.

A reação das seis variedades à inoculação dos oito isolados foi avaliada ao $13^{\circ}$ dia após a inoculação, observandose a segunda folha de cada planta. As leituras da severidade nas folhas basearam-se na escala diagramática proposta por James (1971) para Drechslera avenacea (M. A. Curtis ex Cooke) Shoemaker e D. tritici-repentis (Died.) Shoemaker, a qual baseia-se na percentagem de área foliar lesionada, subdividada em quatro classes, de 1, 5, 25 e 50\%. Para as leituras de tipo de lesão nas folhas foi utilizada a escala de avaliação proposta por Fetch \& Steffenson (1994), porém modificada para $P$. chaetomioides, na qual se atribuíram notas para cada tipo de reação, a saber; nota 2: medianamente resistente, lesões pequenas e alongadas ( 1 x $2 \mathrm{~mm}$, largura versus comprimento) com pequena clorose; nota 4 : medianamente suscetível, lesões mais alongadas $(2 \times 4 \mathrm{~mm})$ e clorose pronunciada; nota 6: suscetível, manchas necróticas pronunciadas (2-4 x 6-8 $\mathrm{mm})$ e clorose.

O delineamento experimental utilizado foi completamente casualizado, com quatro repetições. Os dados obtidos de severidade e tipo de lesão foram transformados para arco seno $(\mathrm{x} / 100)^{2}$. Em seguida, fez-se a análise de variância e compararam-se as médias pelo teste de Duncan a 5\%, considerando os isolados, as variedades e a interação isolados $\mathrm{x}$ variedades, como efeitos principais.

\section{Caracterização enzimática}

Neste teste, os oito isolados foram avaliados quanto às suas atividades amilolítica, lipolítica e proteolítica em meios de cultura sólidos. Para tanto, discos de micélio do fungo com $0,5 \mathrm{~cm}$ de diâmetro, retirados da borda de colônias jovens, foram repicados individualmente para o centro de placas de Petri, para cada um dos três meios sólidos, vedadas e incubadas a $23^{\circ} \mathrm{C}$, durante cinco dias. Foram utilizadas cinco placas para cada meio como repetições dos experimentos.

Para detectar a atividade proteolítica, foi utilizado meio 
Virulência, atividade enzimática e padrões de isoesterases de isolados...

contendo gelatina como substrato (meio nutriente-agar, gelatina 4\%, pH 6,0), como descrito por Hankin \& Anagnostakis (1975). Após o período de cinco dias de incubação do fungo neste meio, foi adicionado sobre o mesmo uma solução saturada de sulfato de amônio, cujo precipitado torna o agar mais opaco e acentua as zonas claras ao redor das colônias, onde a gelatina foi degradada. Para a avaliação da atividade lipolítica, utilizou-se Tween-20 (monolaurato de sorbitan) como substrato. $\mathrm{O}$ meio conteve $10 \mathrm{~g}$ de peptona, $5 \mathrm{~g}$ de $\mathrm{NaCl}$, $0,01 \mathrm{~g} \mathrm{de} \mathrm{CaCl}_{2}, 20 \mathrm{~g}$ de agar, $1000 \mathrm{ml}$ de água destilada e $\mathrm{pH}$ ajustado para 6,0. O Tween-20 foi autoclavado separadamente e adicionado ao meio ( $1 \mathrm{ml}$ para cada $100 \mathrm{ml}$ de meio) momentos antes de vertê-lo às placas de Petri. Após a incubação, as placas foram resfriadas a $4{ }^{\circ} \mathrm{C}$ por $48 \mathrm{~h}$. A atividade das enzimas lipolíticas das colônias foi observada como um precipitado visível devido a formação de cristais de sais de cálcio ou como um halo claro deste precipitado ao redor das colônias. A habilidade para degradar amido foi determinada em meio nutriente-agar, acrescido de $0,2 \%$ de amido solúvel e pH 6,0. Após a incubação do fungo, foi adicionado sobre o meio e em cada placa de Petri, $10 \mathrm{ml}$ de solução alcoólica de iodo. A área amarelada ao redor da colônia, em contraste com o meio azulado, indicou a atividade amilolítica.

A avaliação consistiu na medição de dois diâmetros ortogonais da colônia e do respectivo halo. A atividade enzimática foi estimada semiquantitativamente usando um índice enzimático (I) que expressa a relação do diâmetro médio da colônia pelo diâmetro médio do halo. Deste modo, os isolados com maior índice são os que possuem menor atividade enzimática. Para avaliar a atividade enzimática de lipase, amilase e protease de $P$. chaetomioides, fez-se análise da variância, utilizando o teste de Duncan (5\%), considerando as enzimas e os isolados como efeitos principais.

\section{Eletroforese de Isoenzimas}

Para a obtenção do micélio fresco para extração de enzimas, os isolados foram cultivados em meio BDA, a 23 ${ }^{\circ} \mathrm{C}$. Após sete dias de incubação, uma amostra de $35 \mathrm{mg}$ de cada isolado, contendo todas as estruturas fúngicas, removidos com o auxílio de uma espátula, foi usada para extração enzimática (Valim-Labres, 1995). A análise das isoenzimas de esterase foi por eletroforese horizontal com tampões A (Borato de lítio 0,24 M, pH 8,3) e B (Tris-citrato 0,0595 M, pH 8,3), segundo Scandalios (1969), em gel de poliacrilamida a $6 \%$. A eletroforese foi conduzida por $2 \mathrm{~h}$, com corrente controlada para dar uma diferença de potencial de 10 volts/ $\mathrm{cm}$, sob temperatura de $4{ }^{\circ} \mathrm{C}$, e a migração interrompida quando a linha de frente atingiu $8 \mathrm{~cm}$ do ponto de aplicação. As proteínas presentes nas amostras foram extraídas por trituração manual e homogeneizadas com $60 \mu \mathrm{l}$ dos tampões A e B (1A:9B) e $40 \mu \mathrm{l}$ de azul de bromofenol. Utilizaram-se papéis Whatman $\mathrm{n}^{\circ} 3$ com dimensões de $1 \mathrm{~mm} \times 3 \mathrm{~mm}$ para absorver o homogeneizado de cada amostra e, após este procedimento, foram colocadas no gel. A revelação para esterase foi realizada conforme a técnica de Scandalios (1969) modificada, utilizando os tampões $\mathrm{C}$ (fosfato bibásico, $\mathrm{pH}$ 9,2), a $50 \%$, e D (fosfato monobásico, pH 4,3), a 10\%. Em seguida, o gel foi incubado a $37^{\circ} \mathrm{C}$ por $2 \mathrm{~h}$. Após a coloração, o gel foi lavado e colocado em solução fixadora Ayala (450 $\mathrm{ml}$ de álcool metílico, $110 \mathrm{ml}$ de ácido acético, $340 \mathrm{ml} \mathrm{de}$ água destilada) por $15 \mathrm{~min}$. Para efetuar a análise deste sistema utilizou-se a medida de migração relativa da banda para identificá-la no gel. A análise estatística dos dados de isoenzimas foi feita através da análise de taxonomia numérica (Crisci \& Armengol, 1983), considerando cada banda como uma variável, as quais atribuíram-se valores $0=$ ausência e $1=$ presença, e os isolados como OTUs (Unidades Taxonômicas Operacionais). A similaridade foi medida pelo coeficiente "pareamento simples" (considera tanto ausência como a presença do marcador analisado).

\section{RESULTADOS E DISCUSSÃO}

A análise da variância e os valores médios de severidade evidenciam a variabilidade em virulência entre os isolados e de resistência entre as cultivares utilizadas, além da interação existente entre isolados e cultivares (Tabela 1).

Os isolados de Pyrenophora chaetomioides Iso3-RS e

TABELA 1 - Índice de severidade de doença ${ }^{1}$ de plantas de diferentes variedades de aveia (Avena sativa) após inoculação com isolados de Pyrenophora chaetomioides

\begin{tabular}{lccccccccc}
\hline \hline \multirow{2}{*}{$\begin{array}{l}\text { Cultivar } \\
\text { de aveia }\end{array}$} & \multicolumn{7}{c}{ Isolados de Pyrenophora chaetomioides } \\
\cline { 2 - 9 } & Iso3-RS & Iso1-RS & Iso2-PR & Iso6-PR & Iso7-RS & Iso5-SC & Iso8-SC & Iso4-SC Médias $^{\mathbf{3}}$ \\
\hline UPF-17 & 13,60 & 22,60 & 2,72 & 5,56 & 4,24 & 4,13 & 4,42 & 4,53 & $\mathbf{7 , 7 2}$ a \\
UPF-16 & 9,81 & 6,81 & 5,53 & 7,99 & 4,74 & 2,83 & 4,28 & 1,99 & $\mathbf{5 , 4 9} \mathbf{b}$ \\
UFRGS-15 & 15,56 & 4,67 & 3,13 & 2,17 & 2,71 & 5,53 & 1,96 & 3,74 & $\mathbf{4 , 9 3}$ bc \\
UFRGS-18 & 9,35 & 7,18 & 3,21 & 4,63 & 1,92 & 3,65 & 2,42 & 2,53 & $\mathbf{4 , 3 6}$ bc \\
UFRGS-14 & 12,13 & 5,96 & 5,14 & 2,69 & 3,74 & 1,60 & 1,69 & 1,62 & $\mathbf{4 , 3 2} \mathbf{c}$ \\
Aveia Preta & 5,21 & 5,19 & 7,67 & 1,64 & 3,74 & 1,15 & 2,28 & 1,81 & $\mathbf{3 , 5 9} \mathbf{c}$ \\
Médias & $\mathbf{1 0 , 9 4}$ a & $\mathbf{8 , 7 3}$ a & $\mathbf{4 , 5 7} \mathbf{b}$ & $\mathbf{4 , 1 1}$ bc & $\mathbf{3 , 5 2}$ bc & $\mathbf{3 , 1 4 8}$ bc & $\mathbf{2 , 8 4}$ bc & $\mathbf{2 , 7 0} \mathbf{c}$ & \\
\hline
\end{tabular}

${ }^{1}=$ Valores médios obtidos de acordo com escala diagramática de James (1971).

${ }^{2}=$ Os isolados 1 e 2, 3 e 4, 5 e 6, e 7 e 8 são oriundos de sementes das variedades UFRGS-14, UFRGS-15, UPF-16 e Aveia Preta, respectivamente, seguido da indicação do Estado onde foram cultivadas.

${ }^{3}$ Valores seguidos de mesma letra não diferem estatisticamente pelo teste de Duncan (5\%).

C.V. 30,67\%; (Dados transformados Arco seno raiz x/100).

Valor da probabilidade de $\mathrm{F}$ na interação cultivar $\mathrm{x}$ isolado $=0,0006$ 


\section{C.A. Bocchese et al.}

Iso1-RS foram os mais virulentos, com valores médios de severidade de $10,94 \%$ e $8,73 \%$, respectivamente (Tabela 1 ). A menor severidade foi observada pelo isolado Iso4-SC, com $2,70 \%$. Os demais isolados apresentaram valores intermediários. Os resultados (Tabela 1) sugerem ainda que o local pode ser um fator importante na variação da virulência entre os isolados do fungo, visto que os isolados mais virulentos foram obtidos de variedades do Rio Grande do Sul e, após, com uma tendência decrescente, do Paraná e de Santa Catarina.

Com relação à reação das variedades de aveia, todas foram suscetíveis aos isolados de Pyrenophora chaetomioides, embora tenham diferido entre si quanto aos níveis de severidade (Tabela 1). UPF-17 foi a cultivar mais suscetível, com valor médio de severidade de $7,72 \%$ e a Aveia Preta, a mais resistente, com valor de 3,59\% (Tabela 1). As demais variedades apresentaram valores intermediários de severidade. Lângaro et al. (2000) analisaram a severidade de três isolados de $P$. chaetomioides em 24 genótipos de aveia. Os seus resultados foram semelhantes quanto ao comportamento das variedades analisadas neste estudo.

A interação patógeno-hospedeiro é determinada geneticamente, através dos mecanismos de ataque do patógeno e de defesa da planta. Porém, algumas alterações apresentadas nestas interações podem também ter sido ocasionadas por fatores ambientais aos quais os isolados foram submetidos.

De um modo geral, plântulas que apresentaram lesões maiores também apresentaram maiores valores de severidade, embora a correlação não tenha sido alta (Figura 1), com valor de $r^{2}=0,63$, esta se apresentou significativa ao nível de $1 \%$. Estes dados devem ser interpretados com cautela, visto que o progresso da doença não foi monitorado por um tempo mais longo. Por outro lado, Frank \& Christ (1988) obtiveram correlação maior $\left(r^{2}=0,87\right)$ entre severidade e tipo de lesão com seis linhas e três cultivares de aveia para ambas condições, casa de vegetação e campo. Isto pode indicar que o tipo de lesão pode ser um dos componentes da resistência. Por exemplo, as variedades inoculadas com os isolados Iso3-RS e Iso1$\mathrm{RS}$, que apresentaram os mais altos valores médios de

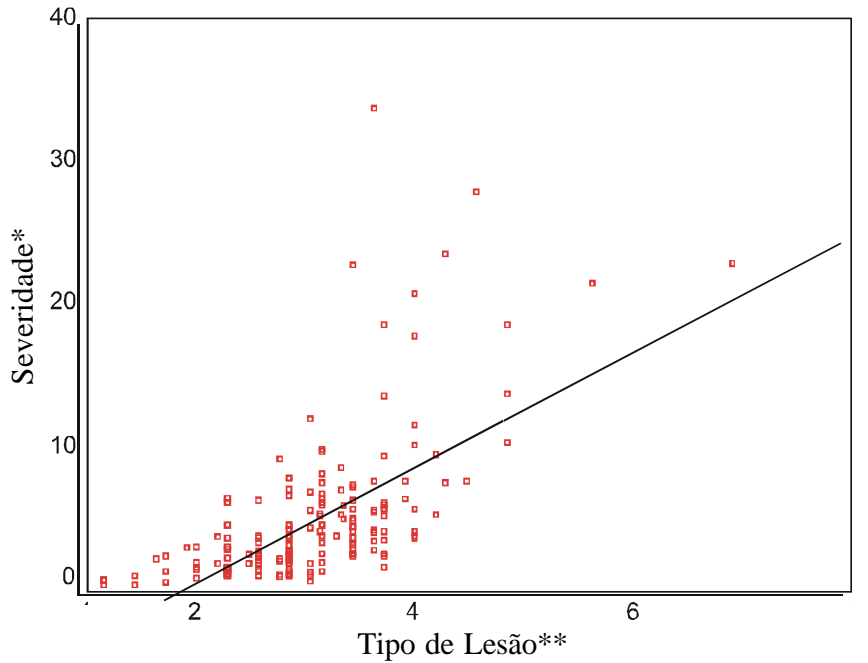

FIG. 1 - Correlação entre tipo de lesão e severidade dos sintomas produzidos em seis cultivares de aveia (Avena sativa) inoculadas com oito isolados de Pyrenophora chaetomioides $\left(\mathbf{r}^{2}=0,630\right)$. * = Severidade medida de acordo com a escala de James (1971).

** = $O$ tipo de lesão seguiu a escala de Fetch \& Steffenson (1994) onde: 2 = moderadamente resistente, $4=$ moderadamente suscetível e 6 = suscetível.

severidade (Tabela 1), também mostraram os maiores valores médios de tipo de lesão (Tabela 2). Analogamente, as variedades inoculadas com ambos os isolados Iso8-SC e Iso5-SC, apresentaram valores menores de severidade e de tipo de lesão. Assim, a UPF-17 apresentou a maior média de tipo de lesão seguida por UPF-16, UFRGS-15, UFRGS-18, UFRGS-14 e Aveia Preta.

Com relação à produção enzimática em meio sólido os isolados Iso3-RS e Iso1-RS, considerados os mais virulentos (Tabelas 1 e 2), destacaram-se dentre os de maior atividade para as três enzimas testadas, lipase, amilase e protease

TABELA 2 - Índice de tipo de lesão ${ }^{1}$ de plantas de diferentes variedades de aveia (Avena sativa) após inoculação com isolados de Pyrenophora chaetomioides

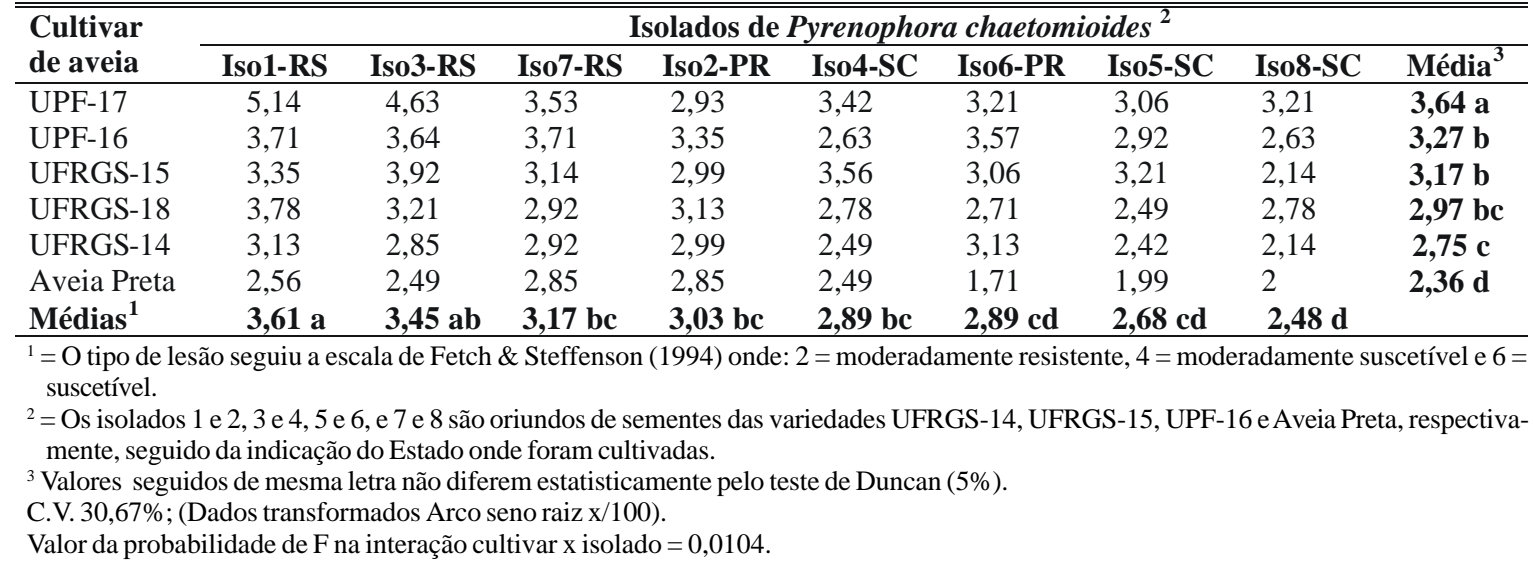


Virulência, atividade enzimática e padrões de isoesterases de isolados...

TABELA 3 - Índices enzimáticos de protease, lipase e amilase de isolados de Pyrenophora chaetomioides

\begin{tabular}{|c|c|c|c|c|c|}
\hline \multicolumn{2}{|c|}{ Lipase } & \multicolumn{2}{|c|}{ Protease } & \multicolumn{2}{|c|}{ Amilase } \\
\hline Isolado & Índice $^{1}$ enzimático & Isolado & Índice $^{1}$ enzimático & Isolado & Índice $^{1}$ enzimático \\
\hline Iso3(RS) & 0,518 a & Iso1(RS) & $0,320 \quad \mathrm{a}$ & Iso1(RS) & 0,790 a \\
\hline Iso2(PR) & $0,627 \quad b$ & Iso3(RS) & 0,359 a & Iso3(RS) & 0,804 \\
\hline Iso1(RS) & 0,648 b c & Iso8(SC) & 0,369 a & Iso6(PR) & 0,890 \\
\hline Iso4(SC) & 0,675 b c d & Iso6(PR) & $0,482 \mathrm{~b}$ & Iso2(PR) & 1,0 \\
\hline Iso7(RS) & 0,681 b c d & Iso4(SC) & $0,514 \mathrm{~b}$ & Iso4(SC) & 1,0 \\
\hline Iso5(SC) & 0,706 b c d & Iso2(PR) & $0,517 \quad b$ & Iso5(SC) & 1,0 \\
\hline Iso8(SC) & 0,726 & Iso7(RS) & $0,536 \mathrm{~b}$ & Iso7(RS) & 1,0 \\
\hline Iso6(PR) & 0,756 & Iso5(SC) & $0,569 \mathrm{~b}$ & Iso8(SC) & 1,0 \\
\hline
\end{tabular}

1) Valores seguidos de mesma letra não diferem pelo teste de Duncan (5\%). O índice enzimático expressa a relação do diâmetro médio da colônia pelo diâmetro médio do halo. Assim, os isolados com maiores índices são os que possuem menor atividade enzimática.

(Tabela 3). Dentre estas, a protease foi produzida em maior quantidade por todos os isolados, seguida da lipase e amilase (dados não apresentados). É possível que a atividade destas três enzimas possa estar diretamente relacionada com o nível de virulência dos isolados. Essa associação entre virulência e atividade enzimática pode desempenhar um importante papel na interação patógeno-hospedeiro.

Independente de $P$. chaetomioides ser um fungo de reprodução predominantemente assexuada, haplóide e heterocariótico, a variabilidade observada na virulência dos isolados estudados, como também a ampla distribuição de bandas nos padrões isoenzimáticos de $\alpha$ e $\beta$ esterases, sugerem que ocorre uma extensiva troca genética nesta espécie. Por este fungo possuir vários núcleos, tanto no micélio quanto nos conídios, características diferenciadas poderiam ser expressas dependendo da informação genética contida nos núcleos presentes em cada célula heterocariótica do patógeno, interagindo com um determinado genótipo do hospedeiro. Sua condição haplóide expressa no fenótipo qualquer alteração, ao contrário do que pode ocorrer em organismos diplóides (Valim-Labres et al., 1997). Além disso, a variação pode ser gerada quando a troca de núcleos é seguida pela fusão nuclear, recombinação somática e conseqüente rearranjo dos cromossomos pela haploidização.

De acordo com Brown et al. (1993), a adaptação do patógeno à resistência do hospedeiro pode resultar da rápida multiplicação de um único indivíduo com os fatores de virulência correspondentes, ou de uma série de indivíduos geneticamente distintos, tendo em comum os referidos genes de virulência. Assim a variação de virulência observada em $P$. chaetomioides, faz com que a segunda hipótese seja mais provável para explicar a adaptabilidade deste patógeno às condições brasileiras. A presença de interação diferencial observada entre isolados e cultivares deste trabalho, no entanto, pode sugerir que a natureza da resistência em aveia a $P$. chaetomioides seja do tipo isolado-especifica.

Através da análise isoenzimática de $\alpha$ e $\beta$ esterases foi possível identificar sete padrões distintos entre os oito isolados (Figura 2). Num outro trabalho (dados não apresentados), grande variabilidade foi observada nestes dois padrões isoenzimáticos de esterase em dez isolados polispóricos de $P$. chaetomioides. Naquele trabalho, não foi estabelecida uma relação entre o padrão isoenzimático de $\alpha$ e $\beta$ esterase com a cultivar hospedeira ou o local de origem. É possível que os resultados tenham sido influenciados pela enzima testada. De acordo com Gillespie \& Langley (1974) a esterase foi enquadrada no grupo II, referido à enzimas que utilizam substratos múltiplos, freqüentemente de origem externa, e que respondem diretamente à diversidade ambiental e, portanto, mais polimórficas. Essa possibilidade, por sua vez, pode representar uma limitação ao uso da esterase para esse fim.

Os isolados Iso7-RS e Iso8-SC, com padrões isoenzimáticos idênticos (Figura 2), apresentaram diferenças na virulência (Tabela 1), e os isolados Iso3-RS e Iso1-RS, com semelhantes níveis de virulência, apresentaram apenas 55\% de similaridade nos padrões isoenzimáticos. Vários autores,
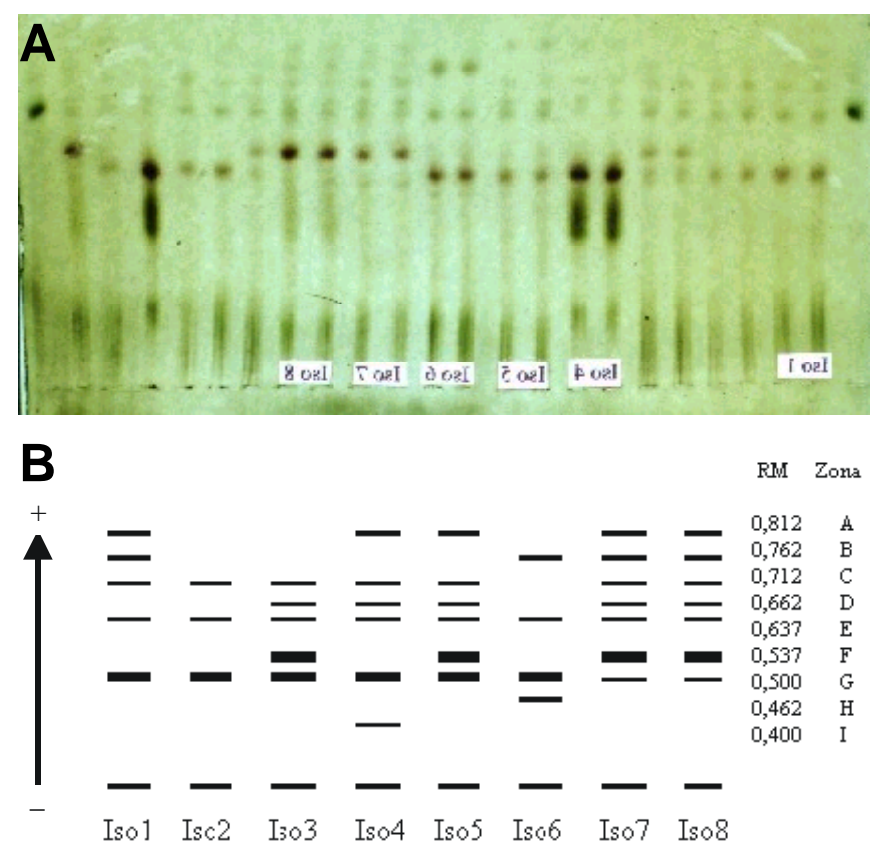

FIG. 2 - Zimograma das isoenzimas de $\alpha$ e $\beta$ esterases de isolados de Pyrenophora chaetomioides obtidos de diferentes cultivares de aveia (Avena sativa) e locais de cultivo. Em A, foto e, em B, esquema representativo da foto. Seta indica sentido da migração. 


\section{C.A. Bocchese et al.}

destacando-se Pereira et. al. (2001), McKeen (1974), Nicholson et al. (1972), demonstraram para os microrganismos Xanthomonas axonopodis pv. manihotis Starr and Garces, Botrytis cinerea Pers. e Venturia inaequalis (Cke.) Wint., respectivamente, através de estudos histoquímicos, a presença de atividade esterásica próximo ao sítio de penetração das células hospedeiras. Em estudos da ultraestrutura da interação patógeno/hospedeiro, Pascholati et al. (1992) relacionaram a presença de esterase junto aos esporos de Erysiphe graminis D.C. f.sp. hordei Marchal, quando da penetração destes nas células hospedeiras. No entanto, embora os trabalhos citados sugiram uma possível associação entre esterase e características que favoreceriam a patogenicidade, neste trabalho não foi possível estabelecer uma associação entre o padrão de esterase apresentado e virulência dos isolados de $P$. chaetomioides testados.

\section{REFERÊNCIAS BIBLIOGRÁFICAS}

ALFENAS, A., JENG, R.S. \& HUBBES, M. Variation in pathogenicity and isoenzyme patterns among isolates of Cryphonectria cubensis. Abstracts, $48^{\text {th }}$ Annual meeting of the Canadian Phytopathological Society. Edmonton, Canada. 1982. p. 303.

ALFENAS, A.C. Virulence and isoenzyme patterns of Cryphonectria cubensis, causal agent of the eucalyptus canker. (PhD Thesis). Toronto. University of Toronto. 1983.

ALFENAS, A.C., JENG, R.S. \& HUBBES, M. Isoenzyme and protein patterns of isolates of Cryphonectria cubensis differing in virulence. Canadian Journal Botany 62:1756-1762. 1984.

BERNIER, L., JENG, R.S. \& RUBBES, M. Differentiation of agressive and nonagressive isolates of Ceratocystis ulmi by gel electrophoresis of intramycelial enzymes. Mycotaxon 17:456-472. 1983.

BROWN, D.K.M., SIMPSON, C.E. \& WOLFE, M.S. Adaptation of barley powdery mildew populations in England to varieties with two resistance genes. Plant Pathology 42:108-115. 1993.

BURDON, J.J. \& ROELFS, A. P. Isozyme and virulence variation in asexually reproducing populations of Puccinia graminis and $P$. recondita on wheat. Phytopathology 75:907-913. 1985.

CRISCI, J.V. \& ARMENGOL, M.F.L. Introduction a la teoria practica de la taxonomia numérica. La Plata. Universidad Nacional de La Plata. 1983.

DEISING, H., NICHOLSON, R.L. \& HANG, M., HOWARD, R.J. \& MENDGEN, K. Adhesion pad formation and the involvemente of cutinase and esterases in attachment of uredospores to the host cuticle. Plant Cell 4:1101-1111. 1992.

ELLIS, M.B. Dematiaceous hyphomycetes. Kew. CAB. 1971.

FETCH, T.G.Jr. \& STEFFENSON, B.J. Identification of Cochliobolus sativus isolates expressing differential virulence on two-row barley genotypes from North Dakota. Canadian Journal of Plant Pathology 16:202-206. 1994.

FRANK, J.A. \& CHRIST, B.J. Rate-limiting resistance to Pyrenophora leaf blotch in spring oats. Phytopathology 78:957-960. 1988.

GILLESPIE, J.H. \& LAGLEY, C.H. A general model for enzyme variation in natural populations. Genetics 76:837-884. 1974.
HANKIN, L. \& ANAGNOSTAKIS, S.L. The use of solid media for detection of enzyme production by fungi. Mycologia 61:597-607. 1975.

JAMES, W.C. An illustrated series of assessment keys for plant diseases: their preparation and usage. Canadian Plant Disease Survey 51:40-65. 1971.

JENG, R.S. \& RUBBES, M. Identification of aggressive and nonagressive strains of Ceratocystis ulmi by polyacrylamide gradient gel electrophoresis of intramycelial proteins. Mycotaxon 17:445455. 1983.

KUNOH, H., YAMAOKA, N. \& YOSHIOKA, H. \& NICHOLSON, R.L. Contact tropism by Erysiphe graminis: release of esterase. International Congress of Plant Pathology, 5. Kyoto, Japão. 1988. pp. 235.

LÂNGARO, N.C., MORAES, M.G., PRESTES, A.M., MARTINELLI, J.A. \& MATSUMURA, A.T.S. Uso de cultivares resistentes no controle da helmintosporiose da aveia. Anais, XX Reunião da Comissão Brasileira de Pesquisa de Aveia, Pelotas, RS. 2000. pp. 160-161.

MAEDA, K.M. Ultrastructural study of Venturia inaequalis (Cke.)Wint. Infection of Malus hosts. (Dissertação de Mestrado). Purdue. Purdue University. 1970.

McKEEN, W.E. Mode of penetration of epidermal cell walls of Vicia faba by Botrytis cinerea. Phytopathology 64:461-467. 1974.

NICHOLSON, R.L., KUC, J. \& WILLIAMS, E.B. Histochemical demonstration of transitory esterase activity in Venturia inaequalis. Phytopathology 62:1241-1247. 1972.

PASCHOLATI, S.F., DEISING, H. \& LEITE, B., ANDERSON, D. \& NICHOLSON, R.L. Cutinase and non-specific esterase activities in the conidial mucilage of Colletotrichum graminicola. Physiological and Molecular Plant Pathology 42:37-51. 1993.

PASCHOLATI, S.F., YOSHIOKA, H., KUNOH, H., NICHOLSON, R.C. Preparation of the infection court by Erysiphe graminis f.sp. hordei: cutinase is a component of the conidial exudate. Physiological and molecular Plant Pathology 41:53-59. 1992.

PEREIRA, A.J., LAPENTA, A.S., VIDIGAL-FILHO, P.S. \& MACHADO, M.F. Differential esterase expression in leaves of Manihot esculenta Crantz infected with Xanthomonas axonopodis pv. manihotis. Biochemical genetics 39:289-296. 2001.

SABESTA, J., ZWARTZ, B., HARDER, D.E., CORAZZA, L. \& RODERICH, H.W. Incidence and resistence of oats to fungus diseases in Europe in 1988-1994. Ochrona Roslin 32:103-113. 1996.

SCANDALIOS, J.G. Genetic control of multiple molecular forms of enzymes in plants. A review. Biochemical Genetics 3:37-79. 1969.

SIVANESAN, A. Graminicolous species of Bipolaris, Curvularia, Drechslera, Exserohilum and their teleomorphs. CABI, Mycological Papers 158. 1987.

VALIM-LABRES, M.E. Variabilidade intraespecífica em Bipolaris sorokiniana: análise morfológica, isoenzimática e de patogenicidade. (Dissertação de Mestrado). Porto Alegre. Universidade Federal do Rio Grande do Sul. 1995.

VALIM-LABRES, M.E., PRESTES, A.M., VAN DER SAND, S. \& MATSUMURA, A.T.S. Variação no aspecto cultural, morfologia e virulência em isolados de Bipolaris sorokiniana de trigo. Fitopatologia Brasileira 22:483-487. 1997.

ZHANG, G. \& BERBEE, M.L. Pyrenophora phylogenetics inferred from ITS and glyceraldehyde-3-phosphate dehydrogenase gene sequences. Mycologia 93:1048-1063. 2001. 